\title{
Norm activation theory in the plastic age: Explaining children's pro-environmental behaviour
}

\author{
Aditya Benyamin $^{1}$, Ratna Djuwita ${ }^{*}$, and Amarina Ashar Ariyanto ${ }^{1}$ \\ ${ }^{1}$ Faculty of Psychology, Universitas Indonesia, Depok, Indonesia
}

\begin{abstract}
Our excessive consumption of single-use plastic has made this era become a plastic age, thus pro-environmental behaviour (PEB) should become our means of survival. This study aims to test whether norm activation theory which is commonly used to explain PEB on adults, could also shed some light in the same behaviour on children sample. Questionnaires, observation, and focus group discussion were used to obtain data from 533 fifth grade students in Jabodetabek, Indonesia. School environment, cultural background, age, length of study, and where the participants live are controlled. Data were then processed through Structural Equation Modelling (SEM). As predicted, norm activation theory has an adequate goodness of fit. Moreover, this study discovers a new interpretation of the theory, that adverse consequence can directly predict personal norm and PEB, due to the malleability of this theory which is further explained in the discussion.
\end{abstract}

\section{Introduction}

Single-use plastic has been ingrained to every aspect of human life. From food and drinking container to groceries bag that we use almost every day. To date, there is 6 tons of plastic all around the world yet only $8 \%$ of that amount is recycled [1]. The rest $80 \%$ become land waste and $12 \%$ more get incinerated which cause air pollution as well. This issue is also contributing the global environmental degradation we are facing today [2], which endanger Indonesia as one the country with the richest biodiversity. Moreover, it's not uncommon to see the tragedy it causes to other species and nature itself too as we can see plastic-eating turtles, fish guts filled with plastic, and sea lions or marine birds entangled by this material that defines our age. Our dependency on this material of plastic in our daily consumption has earned our age the label of the plastic age [3].

Thus, the question we need to ask our self is what we can do to change this state of environmental catastrophe? A more sustainable lifestyle realized through proenvironmental behaviour (PEB), which include minimum to no consumption of single-use plastic, could be the answer to halt this problem [4-5]. Importance of PEB could never be more emphasized as the world already agreed to a more sustainable consumption and production under the SDG number 12 [2]. In order to develop PEB, there are a few

\footnotetext{
*Corresponding author: juwita@ui.ac.id
} 
challenges we must face [5]. First, our education system does not necessarily target at the development of this behaviour. Secondly, it is human nature to think only for the short-term consequences in regard to environmental threats we are facing. Third, each of our individual relatedness to nature is still quite low. Fourth, is that our behaviour is also affected by social norms of where we live and develop. The first and fourth challenges are especially important because norm activation theory [6] is one of the theories commonly used to explain PEB, but no past researches have focused to apply this theory on children sample. Even though, children hold a pivotal role and rights to the well-being of our nature too.

Norm activation theory (NAT) explains PEB is caused by a chain reaction of three variables including adverse consequence (AC), ascribed responsibility (AR), and personal norm (PN) [6]. Adverse consequence is defined as the awareness of oneself to the possible negative consequences to others if one is not acting pro-environmentally. Ascribed responsibility is a sense of responsibility to those possible negative consequences. Both of these variables could be categorized as a set of belief specific to a certain behaviour. Personal norm is a moral obligation for someone to do or to refrain from doing a certain behaviour. In this theory, higher $\mathrm{AC}$ will cause higher $\mathrm{AR}$ as well, and higher PN accordingly. PN will, in the end drive someone to act pro-environmentally which causes a higher rate of PEB. NAT is especially important in explaining PEB as variables specific to a certain behaviour will generate a stronger correlation with the intention to behave or the behaviour itself [7].

School is where we lived and started to develop our morality during childhood, with that in mind, a theory which explains how norm is activated should be put in its place in an educational context. More specifically in a context of environmental education which seeks to shape values, attitudes, and beliefs that affect environmentally ethical behaviours through the development of knowledge and skills which enable someone to participate in sustaining ecologically and socially just society [8]. In Indonesian public schools, environmental education is integrated formally through lectures, discussions, or direct experiences in indoor classes of subjects such as religious and civic studies [9-10]. Only some provinces applied a separated local subject of environmental education [11]. Both deemed to be ineffective due to untrained teachers and discoordination between schools [11]. As an alternative, emerge green schools which have nature-savvy school value in order to give their students familiarity and closeness with nature based on religious teachings of Islam [12]. This might shed some light on a more localized curriculum outside of Western, Educated, Industrialized, Rich, Democratic (WEIRD) samples [13\}. Nevertheless, a further research is required to assess whether these environmental education services are actually creating a positive impact socially and environmentally in order to attain SDG number 12 . As United Nations Environmental Programme suggests, this research could be the first step to conduct a social life-cycle assessment focusing on the psychological impact of environmental education services [14]. This study wanted to test whether NAT works on both types of elementary schools, public, and green.

\section{Method}

\subsection{Respondents}

Purposive and accidental sampling method was used to gather participants of fifth grade students in Jakarta Greater Area (Jabodetabek) which is the capital megapolitan of Indonesia. School level is limited to control age and length of study. Purposive sampling was used to select participating schools. Green schools were selected based on consultation 
with their head of research and development, of which schools represent their concept most. Then, public schools were selected within 2 kilometers radius of each green school based on the database provided by the Indonesian Ministry of Education and Culture. This is done with the purpose of controlling the school environment. Seven public schools and nature schools each was then selected. Accidental sampling was used to select participants, only students with their parent's consent and present at the day of data collection were selected. Moreover, students have to fulfil several criteria of never moved from/to another school(s) along his/her study on elementary level, have lived in Indonesia for minimum 6 years, and was enlisted officially as a fifth-grade student of each participating schools. These criteria were applied to control their cultural background and where they live. After this screening process, 533 participants were then acquired as a sample for this study. Participants demography is considerably balanced with $53.3 \%$ were male and age range varies from 10 13 years old $(\mathrm{M}=10.88)$.

\subsection{Measures}

Quantitative approach was used to measure the variables in this research. Variables measurement included in NAT was adapted to Indonesian language, culture, and the singleuse plastic consumption studied, from questionnaire instrument made by Han for a research on green lodgings behaviour [15]. Participants were required to answer on four-scale options from (1) strongly disagree to (4) strongly agree with the statement of each item. Each option was paired with an emoticon image of (1) frowning face to (4) smiling face to illustrate the options better for children [16]. Out of 12 items included, a sample item for measuring AC is "straw could pollute the land (in Indonesian)." Out of 5 items included, a sample item for measuring AR is "my used straw reduces the quality of nature (in Indonesian)." Out of 4 items included, a sample item for measuring PN is "I must not use a straw to drink (in Indonesian)." All variables, AC (X2 = 5936.871; RMSEA = 0.102; CFI = 0.944; TLI = 0.932; $\mathrm{SRMR}=0.037), \mathrm{AR}(\mathrm{X} 2=1492.301 ; \mathrm{RMSEA}=0.054 ; \mathrm{CFI}=0.995$; $\mathrm{TLI}=0.990 ; \mathrm{SRMR}=0.013), \mathrm{PN}(\mathrm{X} 2=933.006 ; \mathrm{RMSEA}=0.208 ; \mathrm{CFI}=0.950 ; \mathrm{TLI}=$ $0.850 ;$ SRMR $=0.035$ ) have adequate goodness of fit for their measurement model. Additionally, each item has a significant standardized factor loading to each variable, with a range of $0.380-0.908$.

Table 1. PEB self-report norm.

\begin{tabular}{|l|c|c|c|c|}
\hline \multirow{2}{*}{ Behaviour } & \multicolumn{4}{|c|}{ Category/Scoring } \\
\cline { 2 - 5 } & Plentiful (1) & $(2)$ & $(3)$ & Few (4) \\
\hline Plate & $>8$ & $5-8$ & $3-4$ & $0-2$ \\
\hline Glass & $>8$ & $6-8$ & $3-5$ & $0-2$ \\
\hline Straw & $>8$ & $5-8$ & $3-4$ & $0-2$ \\
\hline Bag & $>8$ & $5-7$ & $3-4$ & $0-2$ \\
\hline
\end{tabular}

The PEB measured specifically in this research are consumption of four different single-use plastic including plastic plates, glass, straws, and bags. To quantify these behaviours, two methods were used which are self-report questionnaire and behavioural 
observation. Four items in the questionnaire asked how many of each of those aforementioned single-use plastic product they used in the past week. Participants have to answer with the estimated number of plastics they used. This number was then categorized to four level of consumption from plentiful (1) to just a few (4) based on the date acquired. Detailed norms for each category on every behaviour is shown in Table 1. Each row of the behaviours listed represents the amount of specific products participant used in the past week.

Table 2. PEB observation and FGD norm.

\begin{tabular}{|l|c|c|}
\hline \multirow{2}{*}{ Behaviour } & \multicolumn{2}{|c|}{ Reasons } \\
\cline { 2 - 3 } & Non-Environmentally Friendly & Environmentally Friendly \\
\hline $\begin{array}{l}\text { Non-Environmentally } \\
\text { Friendly }\end{array}$ & 1 & 2 \\
\hline Environmentally Friendly & 3 & 4 \\
\hline
\end{tabular}

PEB was also measured through a structure observation. In the observation process, participants were told that they will be given foods and beverages. Each participant was asked whether they want to use a reusable product or single-use plastic for each behaviour. The reasons why they chose reusable or single-use product were then asked through a Focus Group Discussion (FGD). Scoring based on the behaviours elicited and their reasons are shown in Table 2. Score from both observation and self-report were then combined. Participants with higher scores are considered to behave more pro-environmentally.

\subsection{Procedure}

This study is conducted through mainly four steps after each participant has confirmed their eligibility by submitting the parental consent form. The first step is that all participants were divided into groups of 4-7 students. Each group was accompanied by a research assistant to ensure that they understand each item and instruction, also to guide the FGD session later on. Secondly, participants were instructed to fill out the questionnaire. Third, participants were called one by one to the post where the behavioural observation was done. Each participant was asked to choose a reusable or single-use plastic plate, glass, to use a straw or not, and to use a plastic bag or not. Each participant's answers were noted. In each group, the research assistant will then begin the FGD after all participants have made their choices. Data were then analysed through independent sample t-test in SPSS program.

\section{Results}

Descriptive analysis of each variable measurement showed that participants have quite a high score by passing normative means of 2 out of the maximum score of 4 . Adverse consequence has the mean of $2.85(\mathrm{SD}=.78)$. Ascribed responsibility has the mean of 2.75 $(\mathrm{SD}=0.77)$. Personal norm has the mean of $2.49(\mathrm{SD}=.71)$. Lastly, PEB has the mean of $2.62(\mathrm{SD}=.69)$. 
Table 3. Variables descriptive statistic.

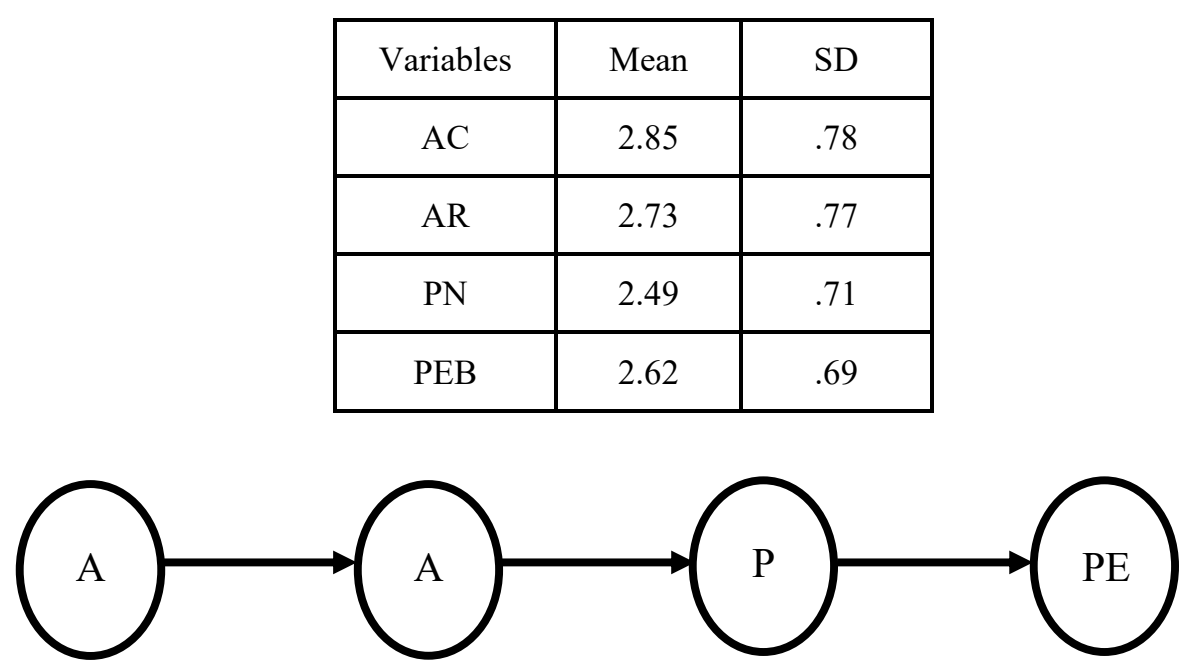

Fig. 1. Norm activation theory $(\mathrm{AC}=$ Adverse Consequence; $\mathrm{AR}=$ Ascribed Responsibility; $\mathrm{PN}=$ Personal Norm; PEB = Pro-Environmental Behaviour).

Next, based on SEM analysis we can see that the NAT model has an adequate goodness of fit $(\mathrm{X} 2=10051.670 ; \mathrm{df}=0.0000 ; \mathrm{RMSEA}=0.063 ; \mathrm{CFI}=0.918 ; \mathrm{TLI}=0.911 ; \mathrm{SRMR}=$ 0.072). It means that this model could be used to explain PEB in children, specifically in Indonesia. There is also a notable difference compared to the original model, where AC could directly correlate to $\mathrm{PN}$.

\section{Discussion}

In this part, it will be discussed why NAT could be applied to explain PEB in a population rarely researched before that is the children sample. The malleability of NAT could be observed through various interpretation in different contexts [17,6]. A sample of different interpretation is how NAT could be applied as a mediator model or moderator model. A mediator model would be interpreted as what has been applied in this study. As for moderator model, interpret NAT where PN correlates with PEB with moderating effect of $\mathrm{AC}$ and $\mathrm{AR}$. It is not quite surprising to see that the mediator model could be interpreted in a different population as there are many possibilities of other interpretation other than these two.

The result showed that $\mathrm{AC}$ negatively correlates directly to PN. Children in Indonesia might have enough environmental education on the knowledge level. But, knowledge alone turns out to make them feel unobligated to behave pro-environmentally. Therefore it can be assumed that eliciting PEB requires a belief of responsible self for the consequence one might cause of not acting pro-environmentally. Though, even this needs further empirical evidence which could be a topic of future research. This difference with the original model could also be caused by the fact that children are only able to comprehend concrete concepts, not abstract ones [18]. Thus, they might not able to differ a sense of obligation (PN)

There are still vast areas to be discovered on the interpretation of NAT. Next study should compare the goodness of fit for different model interpretation or an integration of them, especially in the educational context. This would be best to find out which model 
interpretation to be applied in different contexts. Future studies should also research other models which could also explain PEB on children. Some examples could be the utilization of value-belief-norm (VBN) model [19], theory of planned behaviour (TPB model [20], or incorporating variables which previously have not been integrated to such models such as nature relatedness [21] which is also mentioned as one of the challenges faced in developing PEB [5].

Notable suggestions to be considered in future studies include further psychometric development on the measurement of variables and practical usage in Indonesian schools' curriculum. Better measurement with multiple try-outs should be implemented to ensure better psychometric properties of measurements' validity, reliability, and overall quality. A prior qualitative study to discover Indonesian children's traditional belief related to nature would be preferable to lay down a better foundation for the cultural adaptation of English instruments to Indonesian language and context.

This study should also be able to help schools, both public and green, formulate more focused target on the component variables of NAT. First, there should be a study differentiating the effects and interaction of NAT variables between green schools students and public schools students. Then, we would be able to recommend which variables would need to be improved in which schools. These improvements could be applied by integrating NAT variables in their learning plan, school regulation, and curriculum as a whole. For instance, teachers could use prompts explaining the consequences of single-use plastic thus supporting the development of AC, while the school is establishing the waste segregation policy as what green schools already implemented. Students could also be taught to be responsible to their consumption of single-use plastic by giving them daily task to note down their plastic consumption and clean up their own litters after lunch. Schools could facilitate by providing a template form with illustration to pique their students' interest as what has been done in the construction of measurement instruments in this research [16]. Thus, their sense of responsibility in relation to AR variable could be further developed.

\section{References}

1. R. Geyer, J. R. Jambeck, K.L. Law, Sci. Adv. 3, e1700782 (2017)

2. United Nations, A/RES/70/1 - Transforming our world: The 2030 agenda for sustainable development, https://sustainabledevelopment.un.org/ content/documents/21252030\%20Agenda $\% 20$ for $\% 20$ Sustainable $\% 20$ Development $\% 2$ 0web.pdf (2015)

3. R.C. Thompson, S.H. Swan, C.J. Moore, F.S. von Saal, Philos. Trans. R. Soc. Lond. B. Biol. Sci. 364, 1526 (2009)

4. J. Thøgersen, Euro. Psy. 19 (2), 84 (2015)

5. P.W. Schultz, Cons. Bio. 25 (6), 1080-1083 (2011)

6. J.I.M. De Groot, L. Steg, The J. Soc. Psy. 149 (4), 425-449 (2009)

7. A.M. Norlund, J. Garvill, J. Env. Psy. 23, 339-347 (2003)

8. UNEP, About environmental education and training, http://web.unep.org/training /who-we-are/about-environmental-education-and-training (n.d.)

9. E.K.S.H. Muntasib, B. Masy'ud, S.B. Meilani, E. Rachmawati, Buku ajar pendidikan konservasi (2015)

10. A. Muslicha, Metode pembelajaran dalam pendidikan lingkungan hidup pada siswa sekolah dasar: Studi kasus antara sekolah Jepang di Indonesia dan sekolah adiwiyata di DKI Jakarta (2015) 
11. M. Soerjani, A. Yuwono, Fardiaz, D. Lingkungan hidup: Pendidikan, pengelolaan lingkungan dan kelangsungan pembangunan (2007)

12. Sekolah Alam Indonesia, https://www.sekolahalamindonesia.org/visi-dan-misi/ (n.d.)

13. J. Henrich, S.J. Heine, A. Norencajayan. Behav. and Brain Sci. 33, 61-83 (2010)

14. United Nations Environment Programme, Guidelines of social life cycle assessment of products, http://www.unep.fr/shared/publications/pdf/dtix1164xpa-guidelines_slca.pdf (2014)

15. H. Han. Tour. Man. 47, 164-177 (2015)

16. A.K. Doring, A. Blauensteiner, K. Aryus, L. Drögekamp, W. Bilsky. J. Pers. Ass. 92, 439-228 (2010)

17. K. De Ruyter, M. Wetzels. J. Econ. Psy. 12, 1-22 (2000)

18. D.E. Papalia, G. Manoli. Experience human development (2014)

19. Stern, P. C. Toward a coherent theory of environmentally significant behaviour. J. Soc. Iss., 56 (3), 407- 424 (2000)

20. Ajzen, I. The theory of planned behaviour. Org. Behav. and Hum. Dec. Proc. 50,179211, DOI: 10.1016/0749-5978(91)90020-T (1991)

21. Nisbet, E. K., Zelenski, J. M., \& Murphy, S.A. Env. and Behav. 41 (5): 715-740, DOI: $10.1177 / 0013916508318748$ (2009) 